\title{
Consumo responsável: um passo além do aspecto ambiental
}

\section{Responsible consumption: one step beyond the environmental aspect}

\author{
Abdala Mohamed Saleh ${ }^{1}$ \\ Pascoalina Bailon de Oliveira Saleh ${ }^{2}$
}

\begin{abstract}
RESUMO
Este artigo apresenta um modelo, de cunho didático e dirigido prioritariamente aos profissionais de educação, que leva em conta os diversos aspectos que devem caracterizar um consumo como responsável. Além do usual aspecto Meio Ambiente, há outros, como a Publicidade, a Saúde e a Segurança, o Direito e a Ética e que foram aqui sintetizados a partir da coleção lançada conjuntamente pelo IDEC (Instituto de Defesa do Consumidor) e pelo Inmetro (Instituto Nacional de Metrologia, Normalização e Qualidade Industrial). Essa coleção é dirigida aos professores e alunos do terceiro e quarto ciclos do ensino fundamental e foi elaborada no contexto dos temas transversais apresentados pelos Parâmetros Curriculares Nacionais (PCNs). Colocando-se no papel de consumidor responsável e utilizando-se do referido modelo, inspirado na coleção do IDEC e do Inmetro, pretende-se analisar um caso-exemplo, Ambev, considerada a maior indústria cervejeira da América Latina e "Referência mundial na gestão da água". Por meio desse exemplo, procura-se mostrar que o "respeito à natureza", no caso, o elemento água, é um parâmetro necessário, mas insuficiente para caracterizar um consumo como responsável e que os demais aspectos apontados acima devem ser considerados.
\end{abstract}

Palavras-chave: consumo; cidadania; educação.

${ }^{1}$ Doutor em Física pela Universidade Estadual de Campinas (UNICAMP/SP), professor da Universidade Estadual de Ponta Grossa (UEPG), Brasil. E-mail: abdala.saleh@gmail.com.

${ }^{2}$ Doutora em Linguística pela Universidade Estadual de Campinas (UNICAMP/SP), professora da Universidade Estadual de Ponta Grossa (UEPG), Brasil. E-mail: pbosaleh@gmail.com. 


\begin{abstract}
This paper presents a model of didactic feature and directed primarily to professional education, which takes into account the various aspects that should characterize a responsible consumption. Besides the usual environmental aspect, there are others aspects such as advertising, health and safety, and Law and ethics, which have been summarized from the collection launched jointly by the IDEC (Institute of Consumer Protection) and Inmetro (National Institute of Metrology, Standardization and Industrial Quality). This collection is addressed to teachers and students of the third and fourth cycles of elementary school and was elaborated in the context of cross-cutting themes presented by the National Curriculum Parameters (PCNs). Assuming the role of the responsible consumers and using the referred model, inspired by the collection by IDEC and Inmetro, we intend to analyze the case of AmBev, considered the largest brewery in Latin America and a "global reference in water management". Through this example, we seek to present that the "respect for nature" - in this case the water -, despite being a necessary parameter, is not sufficient to characterize a responsible consumption. Considering the latter, the others aspects raised above should be considered.
\end{abstract}

Keywords: consumption; citizenship; education.

\title{
Introdução
}

Diferentemente do consumo de energia no ser humano, que é conhecido em termos físico-químico-biológicos, cuja análise é realizada com base em critérios racionais e científicos (SILVA, 1995), o consumo do ser humano se dá a partir de fatores menos precisos, racionais e objetivos. Uma complexa rede de fatores leva o ser humano a consumir, tais como a publicidade, as promoções de venda, os planos de crediários etc.

O consumo do ser humano pressupõe a seleção, compra e uso de bens e serviços. Do ponto de vista financeiro-familiar, o comportamento de quem consome deve envolver uma escolha ou uma tomada de decisão, ajustando-se o que se tem para consumir e o que se pode consumir. Dessa forma, é fundamental que haja uma educação num sentido amplo que vise ao consumo com responsabilidade, no qual família, indivíduo ou qualquer grupo social e econômico aprenda a tomar decisões de forma racional com relação ao consumo de bens e serviços; aprenda a "arte" de ser bom comprador; compreenda sobre seus direitos e deveres como consumidor; compreenda a importância de sua função 
como consumidor na economia do país, tendo-se em vista que consumidores mais exigentes produzem países mais competitivos; aprenda a ser um cidadão capaz de contribuir de maneira consciente para a construção de um mercado de consumo mais justo e saudável (SILVA, 1995). A propósito, recentemente o governo elaborou a denominada Estratégia Nacional de Educação Financeira ENEF (BRASIL, 2010), um programa de Estado que aponta para a necessidade de um conjunto de ações com o intuito de educar financeiramente a população. Apesar de extremamente relevante, a educação financeira não será abordada aqui, pois daremos preferência, como veremos, a aspectos menos precisos relacionados ao consumo.

Em termos de educação formal, o tema consumo foi apontado de forma explícita nos chamados PCNs (Parâmetros Curriculares Nacionais), mais especificamente na seção Trabalho e Consumo, dedicada aos Temas Transversais (BRASIL, 1998). Ou seja, esses temas (Ética, Pluralidade Cultural, Meio Ambiente, Saúde, Orientação Sexual e Trabalho e Consumo) são apresentados pelo documento como transversais às várias áreas do conhecimento (Língua Portuguesa, Matemática, Ciências Naturais, Artes, História, Geografia, Educação Física e Língua Estrangeira), ressaltando-se fortemente seu aspecto de urgência social. Para o presente artigo, o tema Consumo, assim como nos PCNs, nos quais se destaca a sua natureza transversal, está conectado diretamente às questões do meio ambiente, da saúde e da ética.

Outra importante fonte para o nosso trabalho é a coleção do IDEC (Instituto de Defesa do Consumidor) e do Inmetro (Instituto Nacional de Metrologia, Normalização e Qualidade Industrial). Trata-se de fascículos que desenvolvem os temas transversais previstos nos PCNs, reorganizando-os em quatro volumes: Meio ambiente e consumo (INMETRO; IDEC, 2002a), Saúde e segurança no consumo (INMETRO; IDEC, 2002b), Publicidade e consumo (INMETRO; IDEC, 2002c) e Direito e ética no consumo (INMETRO; IDEC, 2002d). Esse material é dirigido aos professores e alunos do terceiro e quarto ciclos do Ensino Fundamental e nos serviu de inspiração para formular o modelo gráfico que exporemos abaixo, muito embora as reflexões que aqui realizamos não se restrinjam ao conteúdo dos referidos fascículos.

À primeira vista pode causar certo estranhamento abordar de maneira integrada, por exemplo, o meio ambiente, o consumo e a língua estrangeira. Porém, a visão que divide em seções o nosso amplo conhecimento humano é posta à prova quando temos que abordar questões complexas como as que envolvem o consumo. Entender a dinâmica de consumo em nossa sociedade moderna demanda a utilização de todas as ferramentas disponíveis em nosso universo escolar de forma articulada, no qual os alunos devem estar imersos e serem participantes desse processo de aquisição e geração de conhecimento, 
podendo viabilizar que se tornem consumidores responsáveis de fato. Falar em consumidor responsável não representa apenas uma ação final, mas um conjunto de ações que giram em torno desse conceito, as quais devem envolver a subordinação dos objetivos meramente econômicos "às leis de funcionamento dos sistemas naturais e aos critérios de respeito à dignidade humana e da melhoria da qualidade de vida das pessoas." (GUIMARÃES, 2007, p. 185). Por ser dirigido aos profissionais de educação, neste artigo pretendemos exercitar, do ponto de vista didático, a aplicação dos critérios e leis mencionados.

Dessa forma, em essência, o nosso artigo está inserido no âmbito da educação para um consumo responsável, dirigindo-se em especial aos profissionais de Educação. Pretende-se com ele contribuir para o desenvolvimento de uma visão crítica da noção de consumo responsável, observando-se os papéis desempenhados pelas empresas, produtos e serviços, pois o consumidor exerce a sua cidadania distinguindo e escolhendo empresas ou fornecedores que optem por uma conduta que respeite princípios de um consumo responsável. Para situar essas questões neste trabalho, tomamos como exemplo a empresa Ambev (Companhia de Bebidas das Américas). Elegeremos como elemento de partida para a análise a descrição da empresa realizada por Almeida (2007): "Ambev - Referência mundial na gestão da água”.

\section{Aspectos metodológicos}

Optamos por uma abordagem qualitativa, pois o estabelecimento de um indicador quantitativo de um fornecedor ou produto parece-nos uma tarefa complexa e pouco funcional para nós consumidores "comuns".

Assim, de um ponto de vista qualitativo, o Consumo Responsável pode ser didaticamente apresentado na forma de um fluxograma (ver figura a seguir), tornando de mais fácil compreensão a relação entre os diversos aspectos que os consumidores devem esperar das empresas e dos seus produtos. Levando-os em consideração, um consumidor poderá emitir um parecer de maneira qualitativa, mas suficiente para a tomada de decisão de compra ou uso de bens e serviços.

Como poderemos ver, os itens do modelo reproduzem os títulos dos quatro fascículos da coleção do IDEC e do Inmetro. Nossa contribuição diz respeito à elaboração do fluxograma, o qual ao mesmo tempo sintetiza e explicita a relação entre os diversos componentes do consumo responsável, evidenciando a sua característica multifacetada. Diante disso, podemos interpretá-lo como se segue: 

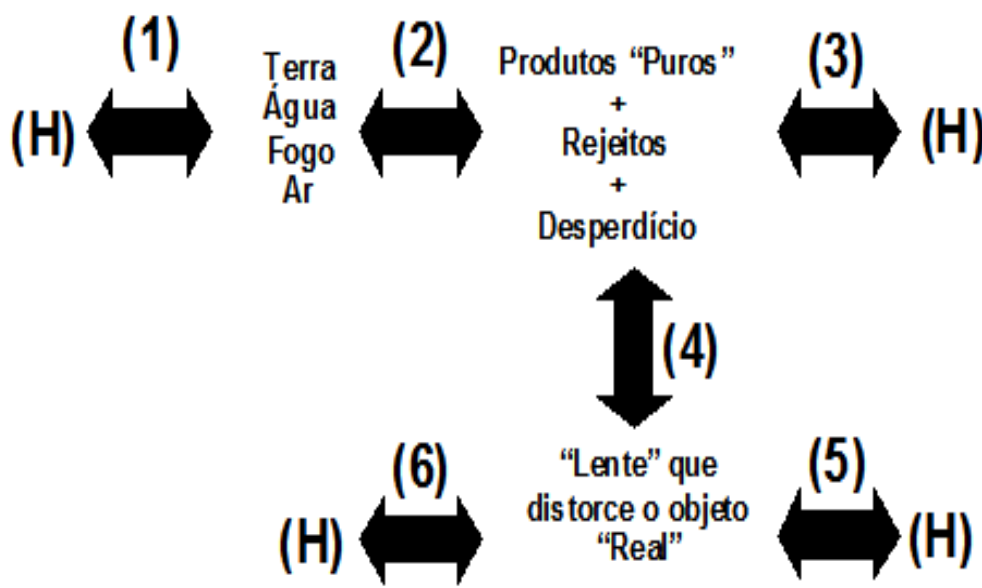

(1): O Homem interage com o sistema natural Terra, Fogo (Energia), Água e Ar. O sistema bidirecional indica que a ação do homem traz alterações ao sistema natural e gera, no próprio homem, novas sensações, atitudes, pensamentos etc.

(2): Na ação do homem sobre o sistema natural, por meio da tecnologia e do conhecimento científico, são gerados Produtos "Puros" (estado ideal em que o que é produzido é totalmente livre de perdas de matéria ou energia), Rejeitos e Desperdício. Esses três elementos não perdem a interação com o sistema natural.

Nos itens (1) e (2) o aspecto MEIO AMBIENTE é considerado.

(3): O homem necessita interagir com esses Produtos "Puros", Rejeitos e Desperdício, entrando em cena o aspecto de sua SAÚDE E SEGURANÇA. Por outro lado, o consumidor pode comprar produtos que impliquem risco à sua saúde, como, por exemplo, um alimento ou um medicamento. Assim, é fundamental tratar, novamente, dos aspectos relacionados à SAÚDE E SEGURANÇA do consumidor, em outras palavras, trata-se do item (6) do fluxograma, ao qual voltaremos abaixo.

(4): O homem necessita apresentar os produtos por ele gerados ao consumidor. Para isso, porém, é necessário que haja uma apresentação que seja vendável, por vezes até pouco esclarecedora, do produto a ser consumido. Aqui se apresenta a vertente $P U B L I C I D A D E$.

(5): O homem produtor e receptor da PUBLICIDADE também interage com sua própria criação publicitária e a de outros, inclusive tornando-se o próprio consumidor dela. 
(6): O homem representa um consumidor final, em termos didáticos. Há no homem aspectos de natureza ética, isto é, suas noções do que é bom e mau, e formulações de leis que regulam a sociedade humana na direção do que é justo. As visões de bem e mal aqui são simplistas, mas fornecem uma noção do necessário neste artigo. Passamos assim a tratar neste caso sobre o tema DIREITOE $\underline{E} T I C A$. Além disso, cada passo, de (1) a (6), é permeado pelo DIREITO e pela ÉTICA como elementos de análise.

Com esse fluxograma é possível colocar, num mesmo plano, diversos aspectos distintos de conhecimento a fim de sistematizar, avaliar e facilitar a nossa tomada de decisão para um consumo responsável.

\section{Resultados e discussão}

Valendo-nos dos itens acima, nesta seção analisaremos a situação da Ambev do ponto de vista do consumo responsável. Para isso, como adiantamos na introdução, tomaremos como parâmetro as características da empresa tal como descrita por Almeida (2007), no caso-exemplo "Ambev - Referência mundial na gestão da água".

Identificação geral da empresa: Ambev - Companhia de Bebidas da Américas. ${ }^{3}$ Maior indústria cervejeira da América Latina e presente em 14 países;

- Receita de R\$ 6 bilhões e forte dependência da perenização dos recursos hídricos.

Ações da empresa que valorizam princípios de um consumo responsável

- Estratifica o consumo por área:

- define prioridades e metas por setor e identifica perdas e vazamentos;

- há metas anuais progressivas por fábrica;

- benchmarks (processo que diz respeito à busca de melhores práticas na indústria que possam conduzir a um melhor desempenho);

- para cada área consideram o tipo de produto, embalagem e tecnologia das instalações;

- Há padronização corporativa para os itens reaproveitamento e projetos e os funcionários são treinados a fim de seguir os "Mandamentos da Água Ambev", que oferecem diretrizes sobre o uso racional da água;

${ }^{3}$ As diversas marcas com as quais a Ambev trabalha encontram-se no site: $<$ http://www. ambev.com.br>. 
- A companhia superou performances mundiais no uso da água para cada litro de cerveja e refrigerante.

- A empresa trabalha com dois tipos de água de:

- processo (preparo das cervejas, refrigerantes etc.);

- serviços (lavagem de tanques): água de reaproveitamento;

- Economia de água em um ano representou o consumo de um mês de uma população de 250.000 habitantes.

Do ponto de vista de nossa análise e aplicação do modelo de fluxograma, que incorporou os temas abordados pela coleção do IDEC e do Inmetro, podemos observar o que segue. $\mathrm{O}$ item (1), que diz respeito à ação do homem sobre o sistema natural, em especial, ÁGUA, está bem representado ao se tomar os elementos supracitados relacionados ao uso racional da água. Consequência natural é verificar uma diminuição do desperdício e um cuidado apropriado com os resíduos associados à água. Outro aspecto importante, que não está explícito acima, é o relacionado ao uso comum de latas de alumínio para refrigerantes e cervejas, que são $100 \%$ recicláveis por um número ilimitado de vezes, reduzindo-se assim efeitos deletérios ao meio ambiente (INMETRO; IDEC, 2002a).

É difícil, através das informações de identificação da empresa acima recolhidas, conhecer os benefícios associados à saúde e à segurança dos trabalhadores (item (3)) que lidam com o uso e reuso da água na Ambev, mas podemos inferir (sem comprovação e não avançaremos nesta busca) que melhores práticas em processos e serviços relacionados à água, com uso apropriado de tecnologia, estejam fortemente ligadas a um maior cuidado com a saúde do homem. Desse ponto de vista, os itens (2) e (3) também estão bem considerados no que tange a um consumo responsável e, até aqui, é possível emitirmos um parecer positivo à empresa Ambev.

Dando prosseguimento à análise guiada pelo fluxograma, devemos considerar de que forma os itens (4), (5) e (6), relacionados à Publicidade, Saúde e Segurança do Consumidor e Direito e Ética no Consumo, respectivamente, são tratados pela Ambev. Para isso, recorreremos às informações oferecidas pela mídia ou por literatura especializada.

A cerveja conseguiu uma posição tão destacada na sociedade mundial que encontramos dados como os da Unicef (Fundo das Nações Unidas para a Infância), de 1993, que demonstram que o custo para suprir, numa década, as necessidades humanas elementares (habitação, alimentação, água limpa, cuidados primários de saúde e educação básica) era inferior ao gasto anual da população americana com o consumo de cerveja (UNICEF, 1993). Neste caso, a campanha publicitária intensiva e bem direcionada certamente desempenhou papel primordial para o desempenho comercial da cerveja nestes dados. 
Para clarearmos o assunto de campanhas publicitárias, vamos tomar algumas análises de anúncios da Ambev $\left(\mathrm{Skol}^{\circledR}\right)$ (GOVATTO, 2007), mais especificamente duas peças relativas às cervejas Bohemia e Antarctica, veiculadas em revista, e uma à Skol, veiculada em televisão. Os anúncios em revista estão de acordo com o Anexo P (vinhos e cervejas) do Código Brasileiro de Autorregulamentação Publicitária ${ }^{4}$ de 2008 e também com o Código de Defesa do Consumidor (IDEC, 1997); por outro lado, o filme veiculado em televisão para a cerveja Skol, ambientado numa praia, tem entre os figurantes um adolescente, o que é proibido pelo Conselho Nacional de Autorregulamentação Publicitária - CONAR.

É preciso considerar que o público jovem é geralmente atraído aos grandes shows patrocinados por várias empresas, entre elas as indústrias que produzem bebidas alcoólicas (INMETRO; IDEC, 2002c). Existe também a situação em que grandes estrelas do esporte são escolhidas como garotos propaganda de marca de cerveja (INMETRO; IDEC, 2002c). Do ponto de vista social e cultural, é no mínimo questionável considerar apropriada esta associação entre esporte e álcool explorada pela publicidade, uma vez que na nossa sociedade o esporte vincula-se ao vigor físico e, portanto, à saúde, enquanto o álcool, por mais que esteja vinculado à ideia de prazer, está também indelevelmente associado a danos à saúde, como veremos abaixo. Por outro lado, aos poucos uma maior consciência acerca do problema do alcoolismo tende a aumentar, como vemos no exemplo do ex-jogador Raí, que resolveu "não mais fazer propaganda de cerveja ou outras bebidas" (TOTTI, 2009, p. 19) depois de visitar jovens da Vila Albertina, na cidade de São Paulo, com o referido problema.

Para o contexto deste artigo, nos limitamos a esses aspectos gerais dos anúncios de cerveja em questão, mas a discussão acima, relativa aos itens (4) $e$ (5) do fluxograma, permite-nos observar que se não levarmos esses aspectos em conta quando avaliarmos a situação da Ambev não estaremos exercendo a nossa condição de consumidor responsável.

Para finalizar nossas considerações sobre esse caso, devemos tratar da SAÚDE E SEGURANÇA DO CONSUMIDOR, relativas ao item (6). Esse elemento avalia as consequências de um produto ou serviço, no caso a cerveja, para o bem-estar individual e coletivo da sociedade, o que de certa forma já foi antecipado quando consideramos a questão da publicidade.

Nos dias de hoje o álcool, ao lado do cigarro (ISSA, 2009), tem seus usos e efeitos bastante discutidos pela sociedade. Aos poucos notamos uma maior

${ }^{4}$ Veja a Resolução N. 02./08 REF. ANEXO "P" Complementa o Anexo "P" - Cervejas e Vinhos, Código Brasileiro de Autorregulamentação Publicitária. Conar, 2008. Disponível em: $<$ http://www.conar.org.br>. 
pressão social para aumentar o controle sobre o consumo de álcool. Ao mesmo tempo, a nossa sociedade convive com um dilema que envolve, por um lado, grandes ganhos econômico-financeiros da indústria de bebidas alcoólicas, especialmente das empresas de cerveja e, por outro, grandes gastos do Estado e, portanto, de todos nós cidadãos pagadores de impostos, no tratamento das consequências negativas relacionadas à ingestão abusiva do álcool. Como dissemos na introdução deste trabalho, o ponto de vista econômico deve ser considerado, mas não em primeiro lugar. Diante disso, vamos destacar aqui alguns aspectos que se referem ao uso de álcool pela população. Segundo Beatriz Cotrim, pesquisadora do Centro Brasileiro de Informações sobre drogas psicotrópicas, "a cerveja é a bebida que inicia o jovem no alcoolismo". (INMETRO; IDEC, 2002b, p. 34).

Há estudos sugerindo que o uso moderado de álcool pode reduzir a incidência de doenças coronarianas, em especial enfartes do miocárdio. Esta redução esta inserida num contexto mais geral de melhorias ou não de indicadores de saúde do organismo do homem, associada ao número de doses diárias: a ingestão de cinco ou mais doses de álcool pode ter como consequência o comprometimento do ventrículo esquerdo do coração, o que pode levar à cardiomiopatia dilatada. ${ }^{5}$ Assim, mesmo considerando que o álcool possa trazer alguns benefícios físicos, é muito difícil haver um controle de dosagem de álcool por parte do usuário. Tal dosagem deveria ser realizada com prescrição e acompanhamento médico.

Do ponto de vista de acidentes automotores, podemos mencionar que um estudo retrospectivo de todas as autópsias realizadas em 1999 mostra que, nos casos de mortes por acidentes de trânsito (Instituto Médico Legal de São Paulo), houve relação com o uso de álcool em 50\% dos óbitos. Hoje este número provavelmente se alterou devido a várias medidas, entre as quais a lei sancionada pelo Presidente da República, chamada "Lei Seca", que proíbe bebidas alcoólicas nas estradas. O texto, que foi aprovado em junho de 2008 pela Câmara dos Deputados, passou a considerar crime conduzir veículos com qualquer teor de álcool no organismo (GUERREIRO, 2008). Após um ano de implementação da lei, o número de mortes e internações provocadas pelo trânsito teve uma redução média de $23 \%$, apontando que ela é eficaz na proteção da vida (FIOCRUZ, 2009). Infelizmente, falhas de fiscalização e na formulação da própria lei favoreceram, em 2010, mais de 40 mil óbitos de pessoas vítimas de acidentes de carro e moto, número nunca antes alcançado (GALVÃO, 2011).

Finalmente, no que se refere ao aspecto $\underline{S A U U D E}$ E SEGURANÇA - item (6) - podemos avaliar, de maneira geral, que os efeitos nocivos do álcool à

${ }^{5}$ De forma mais ampla, pode-se consultar sobre a relação álcool e sistema cardiovascular acessando a página do Centro de Informações sobre Saúde e Álcool. Disponível em: <http://www. cisa.org.br>. 
saúde da sociedade comprometem quaisquer de seus eventuais efeitos positivos. Deste modo, a tensão entre o fator cultural, de prazer, associado ao consumo do álcool versus malefícios individuais e coletivos vem se intensificando, sem uma solução final.

\section{Conclusões}

Ao longo deste texto, abordamos as possíveis nuanças acerca do tema "Consumo Responsável" e esperamos que nossas reflexões possam servir de referência e apoio aos nossos educadores. Destacamos que uma análise mais apurada relativa ao consumo responsável deve ir além do corriqueiro aspecto Meio ambiente, devendo-se incluir também a Publicidade, a Saúde e Segurança e o Direito e a Ética. Como esclarecemos na Introdução, os Parâmetros Curriculares Nacionais inspiraram a elaboração do material do IDEC e do Inmetro, o qual nos forneceu subsídios para a elaboração do nosso modelo.

Nos dias de hoje, a inclusão de ideias relativas ao consumo responsável está sendo cada vez mais absorvida pelos setores industrial, bancário e de serviços. A ideia da presença de um consumidor responsável pode trazer algum desconforto (cada vez menor a cada dia) aos fornecedores de produtos e serviços, imaginando-se que exigências desse tipo de consumidor podem atrapalhar o crescimento de seus negócios. No entanto, não é isto que acontece na prática. Mencionamos no início da introdução a situação dos países desenvolvidos economicamente, nos quais a exigência cidadã dos consumidores qualifica e consolida a competitividade de suas empresas.

Consumidor educado para o consumo traz um bom retorno ao próprio sistema. Esperamos que este trabalho tenha tornado mais claro que uma educação de caráter multidimensional é fundamental para a tomada de decisão, possibilitando uma melhor escolha de produtos e serviços tendo em vista os valores, necessidades e objetivos do cidadão, os quais variam entre indivíduos e grupos sociais e econômicos.

Como já procuramos evidenciar, além do aspecto Meio Ambiente, há outros fatores relevantes para nortear essa decisão, cuja inter-relação foi explicitada por meio do modelo em forma de fluxograma, sugerindo uma possível forma de 
sistematizar e analisar a questão do consumo. De maneira breve, propusemos nesse artigo uma reflexão sobre de que forma a nossa cultura capitalista opera, exemplificada na figura de uma empresa de bebidas (Ambev), que tem reconhecimento internacional por seu programa de gestão de água. $\mathrm{O}$ aumento de lucros e a expansão dos negócios estão embutidos nesta operação, porém, ambos devem estar condicionados aos aspectos relativos ao consumo responsável já mencionados neste artigo (ver itens (1)-(6) tratados em Resultados e Discussões).

Como nossa discussão ao longo do texto sugere, não é possível considerar a Ambev, exemplo de gestão de água, como uma empresa que respeita totalmente princípios de um consumo responsável através, apenas, de critérios relacionados ao meio ambiente: itens (1) e (2) do fluxograma. Respeito à natureza é condição necessária, mas insuficiente para formularmos o cenário de um consumo responsável. Esta lacuna nos levou à proposição de outros ingredientes necessários para uma abordagem mais completa do que constitui um consumo responsável, conforme expusemos nos itens (3)-(6) na seção Aspectos Metodológicos.

Estritamente falando, é pouco provável que cheguemos à satisfação plena do conceito de consumo responsável (também para outros exemplos) tomando como parâmetro o modelo acima. Isto demandaria excluir em definitivo as formas que potencializam um consumo mais descontrolado, comumente aceito e até incentivado pela cultura capitalista em que vivemos. Então, caberia perguntar se o nosso trabalho perde sua utilidade, já que estaremos sempre diante de uma situação de um consumo responsável improvável (ou impossível).

Entendemos que uma das contribuições deste trabalho está em apresentar a questão do consumo responsável dentro de uma escala de medida que permita a coexistência da impossibilidade de um consumo responsável pleno e a possibilidade de algum tipo de consumo responsável. O caso da Ambev se situa neste ponto da escala. No contexto de uma educação que vise a um consumo responsável, é enriquecedor localizar o nosso trabalho entre (e não nos) os dois extremos (totalmente responsável ou totalmente não responsável). O veredicto sim ou não perde significado e se ganha na valorização da riqueza de análises possíveis, tal qual foi nossa condução neste artigo. Acreditamos que esta seja uma condução desejável quando estamos nos referindo à Educação, na qual o fluxo captar $\rightarrow$ analisar $\rightarrow$ interferir $\rightarrow$ captar etc. deve ser contínuo com respeito às informações que se apresentam de forma bastante complexa no mundo ao nosso redor. 


\section{REFERÊNCIAS}

ALMEIDA F. Os desafios da sustentabilidade: uma ruptura urgente. 3. ed. São Paulo: Campus, 2007.

BRASIL. Secretaria de Educação Fundamental. Parâmetros Curriculares Nacionais: terceiro e quarto ciclos: apresentação dos temas transversais. Brasília, DF, 1998.

. Presidência da República. Casa Civil. Subchefia para Assuntos Jurídicos. Decreto n. 7.397, de 22 de dezembro de 2010. Institui a Estratégia Nacional de Educação Financeira - ENEF, dispõe sobre a sua gestão e dá outras providências. Diário Oficial da União, Poder Executivo, Brasília, DF, 23 dez. 2010. Seção 1, Edição Extra, p. 7.

FIOCRUZ. Ministério da Saúde. Lei seca reduz internações e óbitos em mais de 20\%. Brasília, DF, 2009. Disponível em: <http:/www.fiocruz.br/ccs/cgi/cgilua.exe/sys/ start.htm?from_info_index $=141 \&$ infoid $=2594 \&$ sid $=9 \&$ tpl=printerview $>$. Acesso em: 20/10/2009.

GALVÃO, L. Em visita à Câmara, Padilha defende mais rigor na Lei Seca. Portal da Saúde, Brasília, DF, 16 nov. 2011. Disponível em: <http://portalsaude.saude.gov.br/ portalsaude/noticia/3230/162/em-visita-a-camara-padilha-defende-mais-rigor-na-lei-seca.html>. Acesso em: 07/12/ 2011.

GOVATTO, A. C. M. Propaganda responsável: é o que todo anunciante deve fazer. São Paulo: Senac, 2007.

GUERREIRO, G. Lula sanciona lei que proíbe bebidas alcoólicas nas estradas. Folha Online, São Paulo, 19 jun. 2008. Disponível em: < http://www1.folha.uol.com.br/folha/ cotidiano/ult95u414075.shtml>. Acesso em: 22/08/2009.

GUIMARÃES, R. Ética e as dimensões sociais da sustentabilidade. In: FERRARO JUNIOR, L. A. (Org.). Encontros e caminhos: formação de educadoras(es) ambientais e coletivos educadores. Brasília: Ministério do Meio Ambiente, 2007. p. 184-194.

IDEC. Código de Defesa do Consumidor ao seu alcance. São Paulo: Idec, 1997.

INMETRO; IDEC. Meio ambiente e consumo: coleção educação para o consumo responsável. São Paulo: Idec, 2002a.

. Saúde e segurança do consumidor: coleção educação para o consumo responsável. São Paulo: Idec, 2002b.

. Publicidade e consumo: coleção educação para o consumo responsável. São Paulo: Idec, 2002c.

. Direitos do consumidor e ética no consumo: coleção educação para o consumo responsável. São Paulo: Idec, 2002d. 
ISSA, J. S. Reajuste do preço do cigarro é uma das medidas mais efetivas no combate ao tabagismo. Radio CBN, São Paulo, 09 abr. 2009. Disponível em: <http://cbn.globoradio. globo.com/programas/cbn-total/2009/03/26/reajuste-do-preco-do-cigarro-e-uma-das-medidas-mais-efetivas-no-combate-ao-tabagismo.htm>. Acesso em: 18/10/2009.

SILVA, N. M. Subsídios para o estudo da educação do consumidor. Viçosa: Imprensa Universitária da UFV, 1995.

TOTTI, P. O carisma resiste longe dos gramados. Valor Econômico, São Paulo, 04 dez. 2009. EU\&. p.16-21.

UNICEF. Fundo das Nações Unidas para a Infância. Situação mundial da Infância. Nova York, 1993.

Texto recebido em 07 de janeiro de 2010.

Texto aprovado em 07 de março de 2010. 